\title{
Can CFMIP2 models reproduce the leading modes of cloud vertical structure in the CALIPSO-GOCCP observations?
}

\author{
Fang Wang ${ }^{1,2,3} \cdot$ Song Yang ${ }^{4,5}$
}

Received: 28 September 2015 / Accepted: 18 January 2017 /Published online: 13 February 2017

(C) The Author(s) 2017. This article is published with open access at Springerlink.com

\begin{abstract}
Using principal component (PC) analysis, three leading modes of cloud vertical structure (CVS) are revealed by the GCM-Oriented CALIPSO Cloud Product (GOCCP), i.e. tropical high, subtropical anticyclonic and extratropical cyclonic cloud modes (THCM, SACM and ECCM, respectively). THCM mainly reflect the contrast between tropical high clouds and clouds in middle/high latitudes. SACM is closely associated with middle-high clouds in tropical convective cores, few-cloud regimes in subtropical anticyclonic clouds and stratocumulus over subtropical eastern oceans. ECCM mainly corresponds to clouds along extratropical cyclonic regions. Models of phase 2 of Cloud Feedback Model Intercomparison Project (CFMIP2) well reproduce the THCM, but SACM and ECCM are generally poorly simulated compared to GOCCP. Standardized PCs corresponding to CVS modes are generally captured, whereas original PCs (OPCs) are consistently underestimated (overestimated) for THCM (SACM and ECCM) by CFMIP2 models. The effects of CVS modes on relative cloud radiative forcing (RSCRF/ RLCRF) (RSCRF being calculated at the surface while
\end{abstract}

Fang Wang

fangwang@cma.gov.cn

1 Laboratory for Climate Studies, National Climate Center, China Meteorological Administration, Beijing, China

2 Collaborative Innovation Center on Forecast and Evaluation of Meteorological Disasters, Nanjing University of Information Science \& Technology, Nanjing, China

3 Joint Center for Global Change Studies, Beijing, China

4 School of Environmental Science and Engineering, Sun Yat-sen University, Guangzhou, China

5 Institute of Earth Climate and Environment System, Sun Yat-sen University, Guangzhou, China
RLCRF at the top of atmosphere) are studied in terms of principal component regression method. Results show that CFMIP2 models tend to overestimate (underestimated or simulate the opposite sign) RSCRF/RLCRF radiative effects (REs) of ECCM (THCM and SACM) in unit global mean OPC compared to observations. These RE biases may be attributed to two factors, one of which is underestimation (overestimation) of low/middle clouds (high clouds) (also known as stronger (weaker) REs in unit low/middle (high) clouds) in simulated global mean cloud profiles, the other is eigenvector biases in CVS modes (especially for SACM and ECCM). It is suggested that much more attention should be paid on improvement of CVS, especially cloud parameterization associated with particular physical processes (e.g. downwelling regimes with the Hadley circulation, extratropical storm tracks and others), which may be crucial to reduce the CRF biases in current climate models.

\section{Introduction}

Cloud is the primary uncertainty source of climate sensitivity among climate models (e.g. Stephens 2005). This uncertainty mainly originates from the diverse representations of cloud properties and their radiative effects (REs) in climate models, as well as the feedbacks between them and large-scale ambient fields (Wang et al. 2014a). It should also be noted that cloud tuning, a common approach in climate models to achieve a desired radiation balance at the top of atmosphere (TOA) with observations on the global and annual scale, can make the models to neglect some deficiencies in simulating cloud's spatial variability, especially in the vertical dimension (Golaz et al. 2013; Mauritsen et al. 2012). Indeed, cloud vertical structure (CVS) has important effects on radiation and has been long concerned in climate analysis and modelling 
studies (Cesana and Chepfer 2012; Rossow and Zhang 2010; Rossow et al. 2005; Wang et al. 2014b).

Before the revolutionary progress in detecting CVS through satellites with active remote sensors, the CVS was traditionally obtained through ways such as surface weather observations (e.g. Hahn et al. 2001; Warren et al. 1988), passive sensor satellites (e.g. International Satellite Cloud Climatology Project (ISCCP) (Rossow and Schiffer 1999)), analysis of vertical profiles of relative humidity from radiosondes (Wang et al. 2000), observations from the sites of the Atmospheric Radiation Measurement (ARM) (Ackerman and Stokes 2003) and others. However, the CVS information from most of these observations is incomplete for analysis of CVS climatology from the global scale. Although ISCCP dataset has complete spatial and temporal representation, it provides information from a 'top down' viewpoint and only see the uppermost cloud top in each vertical column other than CVS (Rossow and Zhang 2010). Meanwhile, the evaluation of CVS in climate models has mainly focused on the distribution of high, middle and low clouds as defined by ISCCP (Zhang et al. 2005) or cloud vertical profiles constrained in the limited ARM sites (Qian et al. 2012).

The CVS has been actively detected since the launching of CloudSat and CALIPSO (the Cloud-Aerosol Lidar and Infrared Pathfinder Satellite Observation) satellites in the ATrain constellation (Stephens et al. 2002); both of which can provide a global survey of CVS. The CALIPSO, carrying the active Cloud-Aerosol Lidar with Orthogonal Polarization (CALIOP), has a distinct advantage in profiling the clouds with optical depth lower than 3 in the troposphere and lower stratosphere although some limitations still exist (Cesana and Chepfer 2012; Winker et al. 2009). Based on CALIPSO, the GCM-Oriented CALIPSO Cloud Product (CALIPSOGOCCP, hereafter GOCCP) has been developed for cloud evaluation in climate models (Chepfer et al. 2010). GOCCP provides a global $3 \mathrm{D}$ viewpoint of cloud cover, among others, which has been used for cloud evaluation in climate models, focusing mainly on the vertical profile of cloud cover averaged over latitudes or along some cross section (Cesana and Chepfer 2012; Cesana et al. 2012; Chepfer et al. 2008; Kay et al. 2012).

Considering clouds' complex horizontal and vertical structures, principal components analysis (PCA) (or empirical orthogonal function analysis) has been proved an effective method to explore the cloud vertical structure by transforming the multi-level clouds into limited but physically significant CVS modes, which has been applied in GOCCP and two BCC AGCMs recently (Wang et al. 2014b). Under the framework of phase 2 of Cloud Feedback Model Intercomparison Project (CFMIP) (CFMIP2), a part of the CMIP5 (the fifth phase of the Climate Model Intercomparison Project) (Taylor et al. 2012), more standard CFMIP cloud output in GOCCP vertical levels, using the lidar simulator (Chepfer et al. 2008), has been available for a further evaluation of CVS and its REs among CFMIP2 models. In view of this, the work in Wang et al. (2014b) has been extended to multiple CFMIP2 models but with updated physical interpretations to answer how CFMIP2 models reproduce the leading CVS modes and what radiative effects can be made by the simulation deficiencies in CVS modes.

The remainder of this study is arranged as follows. The data and methodology used for comparisons between CFMIP2 models and GOCCP are described in Sect. 2. Results are shown in Sect. 3, including evaluation on CVS and its REs in CFMIP2 modes, as well as related discussions. Finally, a summary is given in Sect. 4.

\section{Data and methodology}

\subsection{Data}

GOCCP was developed from the CALIPSO level 1 products for special purpose in cloudiness evaluation in climate models under the CFMIP framework (Chepfer et al. 2010). The GOCCP monthly cloud cover used in this study has a vertical resolution of $480 \mathrm{~m}$ (40 vertical levels) and a horizontal resolution of $2^{\circ} \times 2^{\circ}$, from June 2006 to December 2010. The data are available at the website of CALIPSO-GOCCP (http://climserv.ipsl.polytechnique.fr/cfmip-obs/Calipso_ goccp.html).

Monthly cloud covers (1979-2008) from 11 CFMIP2 models (Table 1) are also selected for our study. These data came from the AMIP experiment of CMIP5 and only the r1ilp1 ensemble was used. Unlike other AMIP variables, the CFMIP2 clouds are additional output of a lidar simulator embedded in those models. The lidar simulator is one of the simulators of CFMIP Observational Simulator Package (COSP) (BodasSalcedo et al. 2011), being specially used to simulate the cloud cover in model atmosphere just as observed by the CALIPSO. Cloud cover output from lidar simulator in CFMIP2 models is consistent with that in GOCCP in both physics and resolution, facilitating direct comparisons between them.

The corresponding radiative fluxes from 11 CFMIP2 models are used to derive the cloud REs. The monthly CERES Energy Balanced and Filled (EBAF) surface and TOA L3B Ed2.6r data products (Kato et al. 2013), specially designed for the intercomparison of radiative fluxes between satellite-based estimates and model simulations, are used as the reference data. The CERES data sets have a spatial resolution of $1^{\circ} \times 1^{\circ}$ latitude/longitude and time periods from March 2000 to February 2010 for surface data and from March 2000 to June 2012 for TOA data. 
Table 1 Description of CFMIP2 models and cloud cover schemes

\begin{tabular}{|c|c|c|c|c|}
\hline No. & Model ID & Country & $\begin{array}{l}\text { Atmospheric } \\
\text { model resolution }\end{array}$ & Cloud cover scheme \\
\hline 1 & BCC-CSM1.1 & China & T42, L26 & $\begin{array}{l}\text { Diagnostic scheme treating marine } \\
\text { stratocumulus, convective, and layered } \\
\text { clouds separately (Wang et al. 2014b). }\end{array}$ \\
\hline 2 & BCC-CSM1.1(m) & China & T106, L26 & Same as BCC-CSM1.1 \\
\hline 3 & CanAM4 & Canada & T63, L35 & $\begin{array}{l}\text { Statistical cloud scheme (von Salzen et al. } \\
\text { 2013). }\end{array}$ \\
\hline 4 & GFDL-CM3 & USA & C48, L48 & Prognostic cloud scheme (Donner et al. 2011). \\
\hline 5 & HadGEM2-A & Britain & N96, L38 & $\begin{array}{l}\text { Parameterized RH-crit and vertical gradient } \\
\text { area cloud scheme (Martin et al. 2006). }\end{array}$ \\
\hline 6 & IPSL-CM5A-LR & France & $\begin{array}{l}3.75^{\circ} \times 1.875^{\circ} \\
\quad \mathrm{L} 39\end{array}$ & $\begin{array}{l}\text { Statistical cloud scheme based on a PDF of } \\
\text { total water content (Dufresne et al. 2013). }\end{array}$ \\
\hline 7 & IPSL-CM5A-MR & France & $2.5^{\circ} \times 1.25^{\circ}, \mathrm{L} 39$ & Same as IPSL-CM5A-LR \\
\hline 8 & IPSL-CM5B-LR & France & $\begin{array}{l}3.75^{\circ} \times 1.875^{\circ} \\
\quad \mathrm{L} 39\end{array}$ & $\begin{array}{l}\text { Statistical cloud scheme coupled to convection } \\
\text { scheme and boundary scheme with different } \\
\text { PDFs (Dufresne et al. 2013). }\end{array}$ \\
\hline 9 & MIROC5 & Japan & $\mathrm{T} 85, \mathrm{~L} 40$ & $\begin{array}{l}\text { PDF-based hybrid prognostic cloud scheme } \\
\text { (Watanabe et al. 2009). }\end{array}$ \\
\hline 10 & MPI-ESM-LR & Germany & T63, L47 & $\begin{array}{l}\text { Diagnosed as a function of RH (Stevens et al. } \\
\text { 2013). }\end{array}$ \\
\hline 11 & MRI-CGCM3 & Japan & $\begin{array}{l}\text { TL159 } \\
\left(1.125^{\circ} \times 1.12-\right. \\
\left.5^{\circ}\right), \text { L48 }\end{array}$ & $\begin{array}{l}\text { PDF-based and Tiedtke cloud scheme } \\
\text { (Yukimoto et al. 2011). }\end{array}$ \\
\hline
\end{tabular}

\subsection{Methods}

\subsubsection{Data processing and definitions}

The annual mean cloud cover in GOCCP is computed from the period of January 2007 to December 2010, and the period of January 2001 to December 2008 is used to calculate the annual means of cloud cover in CFMIP2 models and radiative fluxes in both CERES and models. The multi-model ensemble (MME) is the equal-weighted average of individual models. In order to compare easily, both the GOCCP and the model output are linearly interpolated to the same horizontal resolution of $1^{\circ} \times 1^{\circ}$ latitude/longitude as the CERES radiative fluxes.

The cloud REs in this study are represented by relative shortwave (SW)/longwave (LW) radiative forcing (RSCRF/ RLCRF) (Wang et al. 2014b), RSCRF being calculated at the surface while RLCRF at the TOA, that is:

$$
\begin{aligned}
& \text { RSCRF }=\frac{S W_{d n, a l l}-S W_{d n, c l r}}{S W_{d n, c l r}} * 100 \\
& \text { RLCRF }=\frac{L W_{u p, \text { all }}-L W_{u p, c l r}}{L W_{u p, c l r}} * 100
\end{aligned}
$$

where $\mathrm{SW}_{\mathrm{dn}, \text { all }}$ and $\mathrm{SW}_{\mathrm{dn}, \mathrm{clr}}\left(\mathrm{LW}_{\text {up,all }}\right.$ and $\left.\mathrm{LW}_{\text {up,clr }}\right)$ indicate the all-sky and clear-sky surface (TOA) downwelling SW (upwelling LW) radiation fluxes respectively.

\subsubsection{Principal component analysis (PCA)}

The central idea of PCA is to reduce the dimensionality of a data set with a large number of interrelated variables while retaining maximum variation of the data set. In this study, PCA is used to transform the 40-level cloud cover to limited vertical modes (i.e. eigenvectors, EVs hereafter) and horizontal projections of these modes (i.e. principal components, PCs hereafter).

Let $X_{m n}$ be the cloud cover matrix with $m$ vertical levels and $n$ horizontal grid points, by linear transformation, the PCs can be expressed as

$P_{m n}=V_{m m}^{\prime} \times X_{m n}$

where $V_{m m}^{\prime}$ is the transpose of eigenvector matrix $V_{m m} . V_{m m}$ is composed of $\mathrm{m}$ eigenvectors, $v_{k}=\left(v_{1 k} v_{2 k} \ldots v_{m k}\right)^{\prime}$, $k=1,2, \ldots, m$. The corresponding eigenvalues, $\lambda_{k}, k=1,2, \ldots, m$, satisfy $\lambda_{1} \geq \lambda_{2} \geq \ldots \geq \lambda_{m}$ and can be obtained by solving the following polynomial equation:

$|A-\lambda I|=0$

where $A$ and $I$ denote the covariance matrix of $X_{m n}$ and identity matrix, respectively.

The derived PCs are uncorrelated and are ordered based on $\lambda_{k}$ so that the first few ones contain most of the variation in 
original variables. In this study, PCs are first calculated from standardized cloud cover field (hereafter SPC), and then the corresponding original PCs (hereafter OPC) are recovered by reversing the standardization formula. The SPC and OPC reflect the relative and actual horizontal distribution patterns of CVS mode, respectively.

\subsubsection{Principal component regression (PCR)}

PCR is further used to investigate the effects of independent PCs on radiation to eliminate the impacts of collinearity between cloud vertical levels on regression. PCR is basically identical to a standard linear regression model but using PCs as explanatory variables, which can be formulated as

$Y=b_{0}+\sum_{k=1}^{m} b_{k} P_{k}$

where $Y$ is a dependent variable (RSCRF or RLCRF in this study), $P$ denotes explanatory variables (i.e. PCs in the previous section), $b_{0}$ is the regression constant, $b_{k}$ indicates regression coefficients and $m$ is the number of explanatory variables.

The standardized regression coefficients $\left(b_{k}^{\prime}\right)$ can also be obtained through above regression model with standardized dependent and explanatory variables, which is related to $b_{k}$ as

$b_{k}^{\prime}=b_{k} \frac{S_{P_{k}}}{S_{Y}}$

where $S$ denotes the standard deviation of a given variable.

\section{Results}

\subsection{CVS modes in GOCCP}

The first three EVs and their SPCs in GOCCP and CFMIP2 models are shown in Figs. 1 and 2. All the CVS modes are statistically significant based on the North Test (North et al. 1982). First three GOCCP EVs explain $80.6 \%$ of the total variance and well represent the original cloud cover field.
The CVS modes are basically consistent with those in Wang et al. (2014b), but with much more detailed description in this study to further understand the physics of these modes.

The leading CVS mode (EV1 42.3\%) depicts a vertical pattern with opposite-sign eigenvectors divided by the height around $10 \mathrm{~km}$ (Fig. 1a). The negative values of PC1 (corresponding to the negative phase of EV1) are mainly located in the latitudes between $30^{\circ} \mathrm{S}$ and $30^{\circ} \mathrm{N}$, characterized by high clouds in the tropical deep convective regions along the InterTropical Convergence Zone (ITCZ). The positive SPC1 values (corresponding to the positive phase of EV1) in the middle and high latitudes (Fig. 2 (m1)) are linked to the deep and continuous clouds around $60^{\circ}$ latitudes, extending from the PBL to about $10 \mathrm{~km}$. EV1 also reflects the descending of maximum cloud-top height corresponding to the decrease in troposphere height from around $17 \mathrm{~km}$ in the tropics to about $10 \mathrm{~km}$ in the middle-high latitudes (Dessler et al. 2006).

The second CVS mode (EV2 26.2\%) is characterized by strong negative eigenvectors through levels above $3 \mathrm{~km}$ and with the peak around $7 \mathrm{~km}$ (Fig. 1b), corresponding to the middle-high clouds in the tropical convective cores (Fig. 2 (m2)). On the contrast, the positive eigenvectors are much weaker and are located in the planetary boundary layer (PBL) (Fig. 1b), corresponding to the main subtropical anticyclonic regions in SPC2 (Fig. $2(\mathrm{~m} 2)$ ), where the formation of middle to high clouds are depressed. In addition, positive eigenvectors are also indicative of the PBL marine stratocumulus clouds over the subtropical eastern oceans (Wood 2012). It is also found that the high-SPC-value regions correspond well to the main strong upwelling/downwelling regimes over oceans (Dolinar et al. 2015).

The third CVS mode (EV3, 12.1\%) portraits a two-peak structure for both the positive and negative eigenvectors (Fig. 1c). One of the positive (negative) peaks is located at

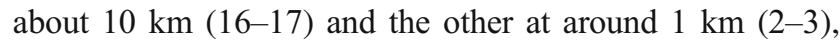
corresponding to upper-level clouds and low-level clouds, respectively. The relevant positive values in SPC 3 are typically located in extratropical cyclonic regions (Fig. 2 (m3)), implying a close linkage between EV3 and extratropical cyclonic
Fig. 1 First three leading modes of cloud cover vertical structure simulated by 11 CFMIP2 models and their MME, and observed by GOCCP. Horizontal axis denotes values of eigenvector. Horizontal dashed lines indicate boundaries of ISCCP high, middle and low clouds at 3.36 and $6.72 \mathrm{~km}$, respectively. Grey shadings denote EV spread among models at a given level
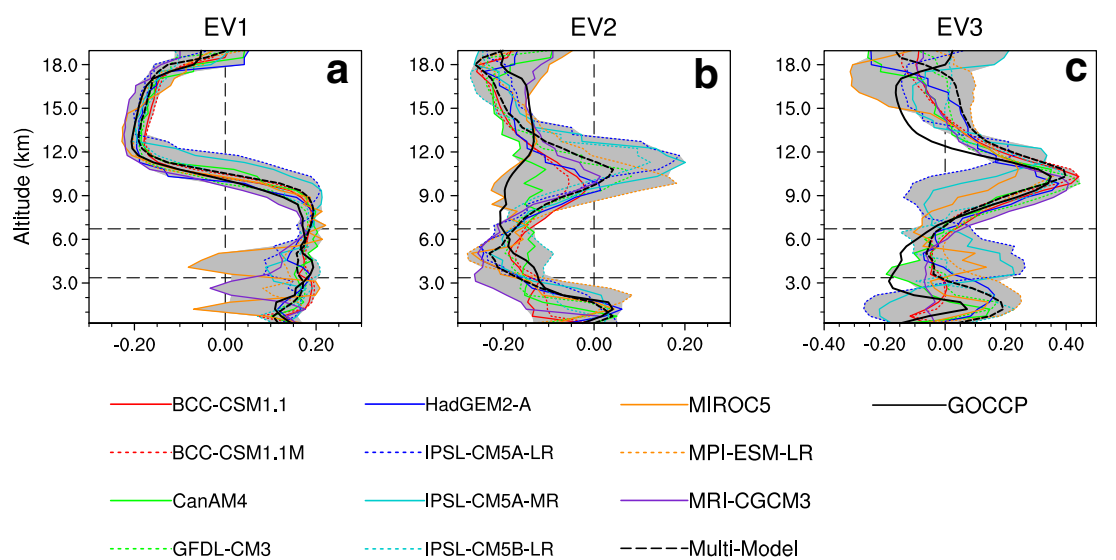

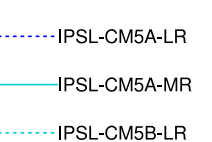

(.......-MPI-ESM-LR

MRI-CGCM3 


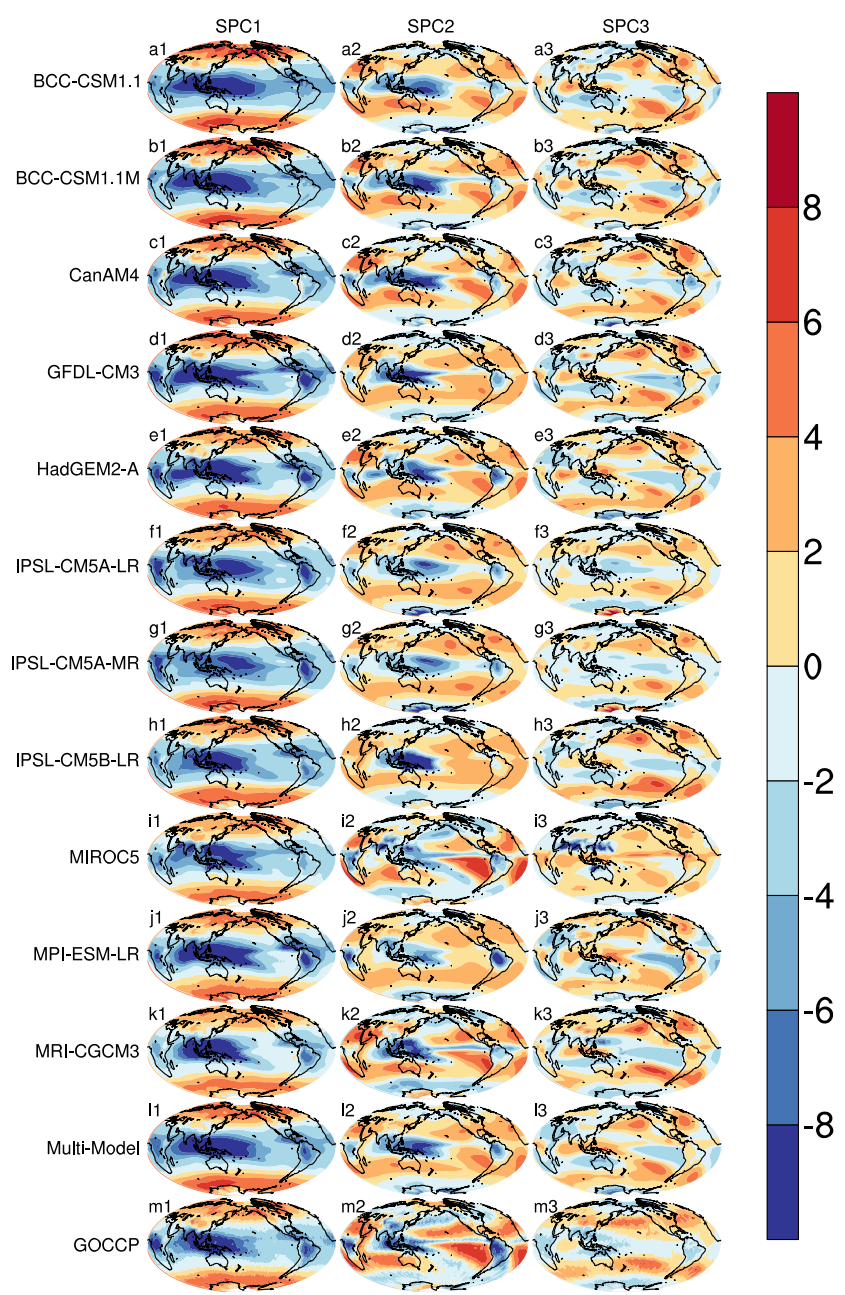

Fig. 2 First three SPCs simulated by 11 CFMIP2 models and the MME, and observed by GOCCP

clouds, whereas negative values are in tropical deep convective regions and polar regions. The positive two-peak structure is consistent with the asymmetric dipole structure of midlatitude storm-track cloud systems revealed by A-Train observations (Huang et al. 2014).

Given the close association of the first three EVs with tropical high, subtropical anticyclonic and extratropical cyclonic clouds, we introduce the term of tropical high cloud mode (THCM), subtropical anticyclonic cloud mode (SACM) and extratropical cyclonic cloud mode (ECCM), respectively.

\subsection{Evaluation on CVS modes in CFMIP2 models}

The total variances explained by the first three EVs in CFMIP2 models vary from 69.6 to $86.7 \%$, most of which exceed $80.0 \%$ except for two IPSL-CM5A models, MIROC5 and MRI-CGCM3 (Table 2). For individual EV, most models (except for MIROC5 and MRI-CGCM3) overestimate the explained variances in THCM, whereas all models underestimate those of SACM remarkably.
Table 2 Percentages of variance explained by the first three EVs in CFMIP2 models and CALIPSO-GOCCP

\begin{tabular}{lllll}
\hline Model & EV1 $(\%)$ & EV2 $(\%)$ & EV3 $(\%)$ & Total $(\%)$ \\
\hline BCC-CSM1.1 & 55.0 & 19.9 & 11.9 & 86.7 \\
BCC-CSM1.1M & 54.4 & 20.9 & 11.3 & 86.6 \\
CanAM4 & 47.5 & 18.8 & 13.7 & 80.0 \\
GFDL-CM3 & 56.6 & 17.0 & 12.1 & 85.7 \\
HadGEM2-A & 48.3 & 19.0 & 13.7 & 81.0 \\
IPSL-CM5A-LR & 44.3 & 20.6 & 10.7 & 75.5 \\
IPSL-CM5A-MR & 45.2 & 21.0 & 9.8 & 76.0 \\
IPSL-CM5B-LR & 45.4 & 20.2 & 14.4 & 80.0 \\
MIROC5 & 36.1 & 20.3 & 13.3 & 69.6 \\
MPI-ESM-LR & 51.0 & 17.6 & 11.6 & 80.1 \\
MRI-CGCM3 & 38.1 & 23.8 & 13.7 & 75.7 \\
MME & 52.6 & 18.4 & 12.8 & 83.7 \\
GOCCP & 42.3 & 26.2 & 12.1 & 80.6 \\
\hline
\end{tabular}

All the models have excellent skills in capturing the CVS features of THCM (Fig. 1a), except that two models (IPSLCM5A-LR and IPSL-CM5A-MR) seem to simulate a slightly higher cloud top height at middle to high latitudes. In addition, the positive eigenvectors in THCM exhibit obvious discontinuity in two models, i.e. MRI-CGCM3 and MIROC5. SPCs are generally successfully reproduced by all the models, especially the deep convective cores along the ITCZ (Fig. 2).

With respect to SACM, most models successfully simulate the basic features: few-cloud regimes over the subtropical anticyclonic regions, PBL stratocumulus clouds over the subtropical eastern oceans and the negative SPC pattern in tropical convective cores (Figs. $1 \mathrm{~b}$ and 2). However, most models produce lower peaks of negative eigenvectors (between 3 and $6 \mathrm{~km}$ ) than that around $7 \mathrm{~km}$ in GOCCP, as well as much weaker negative eigenvectors around 9-12 km. Some models (e.g. three IPSL models and MPI-ESM-LR) even simulate a false peak of positive eigenvectors around 9 to $12 \mathrm{~km}$.

The basic two-peak structure of positive eigenvectors in ECCM is captured by most of models except five models (two BCC models, two IPSL-CM5A models and the MRICGCM3), failing to simulate the peak in PBL (Fig. 1c). In addition, remarkable insufficiencies are found in simulations of the two negative-eigenvector peaks (Fig. 1c). SPCs corresponding to the positive EV3 phase are generally captured along extratropical cyclonic regions, whereas those relative to the negative phase are not well simulated in most of models especially along ITCZ convective cores (Fig. 2).

Taylor diagrams (Taylor 2001) are further applied to provide a quantitative evaluation of the simulated SPCs in CFMIP2 models and GOCCP. As expected, models have the best performance in simulating THCM SPCs, with spatial correlation coefficients above 0.90 between GOCCP and models and with less spread among models (Fig. 3a). The 

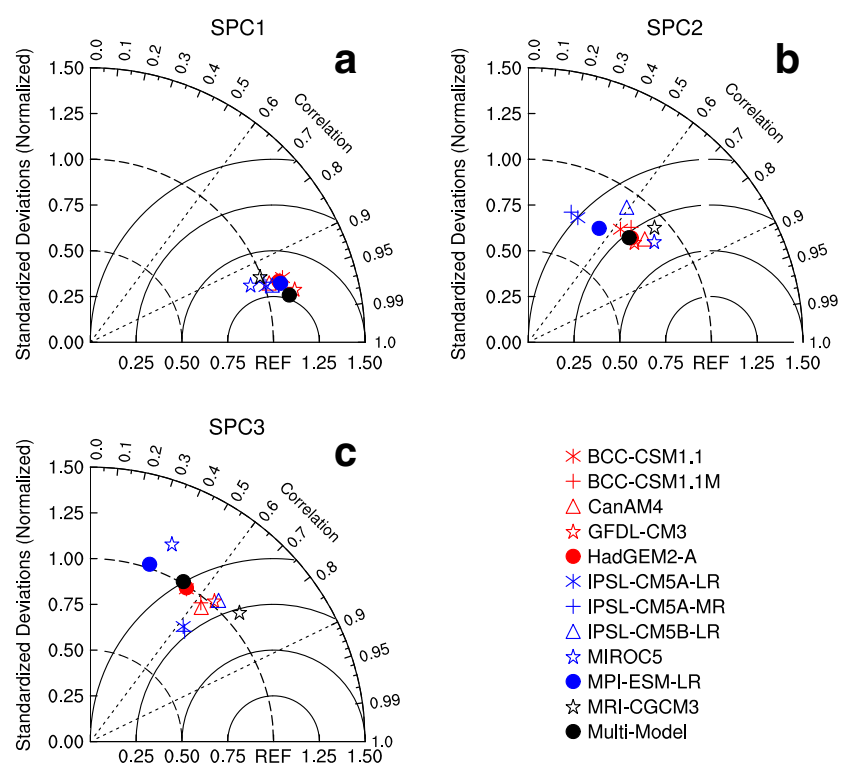

Fig. 3 Taylor diagram for the first three SPCs simulated by 11 CFMIP2 models and the MME, where the reference fields are from GOCCP. The abscissa denotes the pattern standard deviation ratio, and the azimuthal angle indicates the pattern correlation coefficient

inter-model spread becomes larger and spatial correlations decrease remarkably in SACM and ECCM (Fig. 3b, c), being closely associated with the large divergence in simulating SACM and ECCM among models (Fig. 1b, c).

Similar analysis is also made on OPCs (Figs. 4 and 5). It is found that spatial patterns are basically consistent between OPCs and SPCs (Figs. 2 and 4), whereas the magnitude, pattern standard deviation ratio and centred root-mean-square error of OPCs diverge greatly compared to SPCs, indicating large differences in both OPC mean bias and spatial dispersion in models relative to GOCCP. In addition, pattern standard deviations of all three OPCs in most CFMIP2 models are simulated larger than that in GOCCP. It also noted that global mean OPC1 (OPC2 and OPC3) are consistently underestimated (overestimated) by all models (most of models) compared to the observed value(s) of $9.5 \%(-25.7$ and $3.2 \%$ ) (Table 3 ), which may contribute greatly to simulated RSCRF/RLCRF biases in the following sections.

\subsection{Radiative effects of CVS modes in CFMIP2 models}

Both the ordinary and standardized linear equations are constructed between OPCs and RSCRF/RLCRF for CFMIP2 models and GOCCP data, producing ordinary and standardized regression coefficients (RCs and SRCs), respectively. RCs depend on the dispersion of dependent and explanatory variables, denoting the SW extinction efficiency (mainly determined by extinction optical depth (EOD)) for RSCRF or LW emission efficiency (mainly depending on cloud top temperature or cloud top height) for RLCRF by unit OPC, whereas standardized PCR removes the effects of variables' average

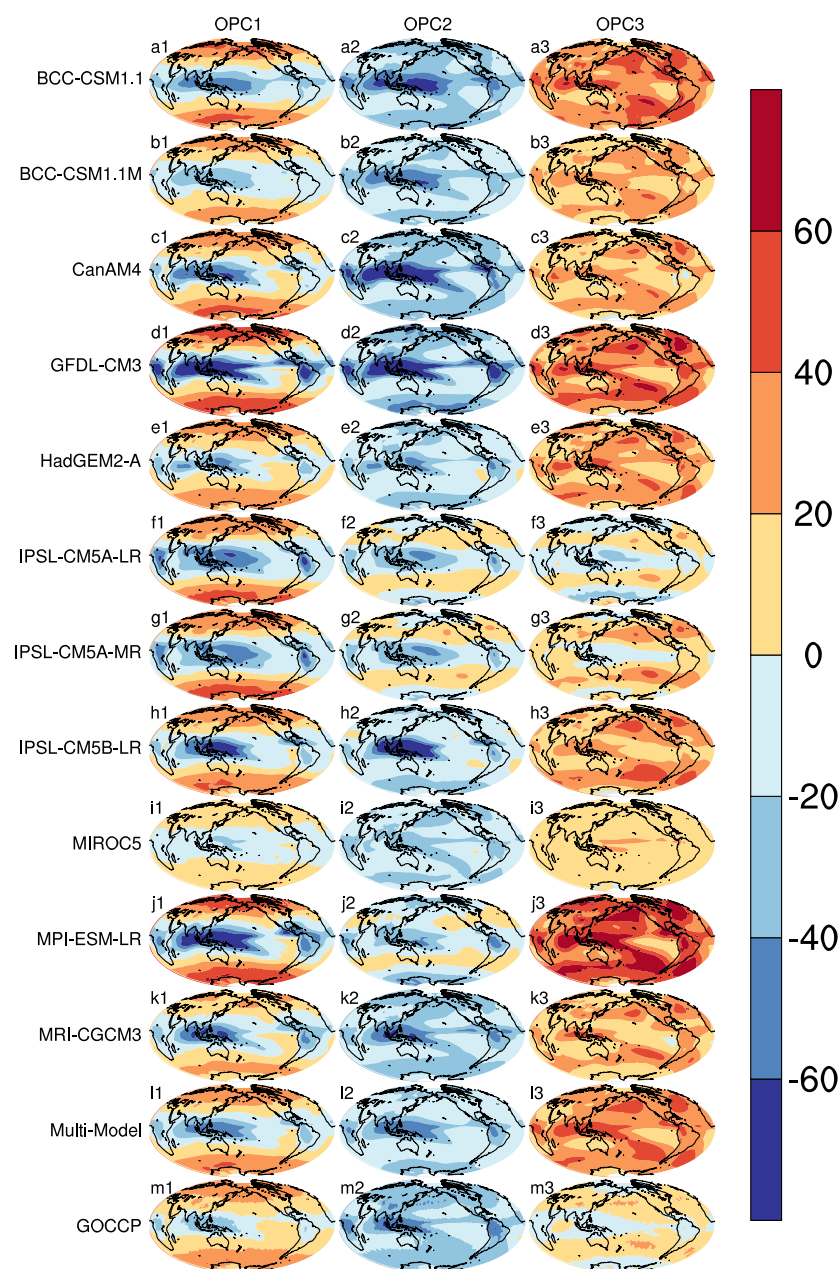

Fig. 4 First three OPCs simulated by 11 CFMIP2 models and the MME, and observed by GOCCP
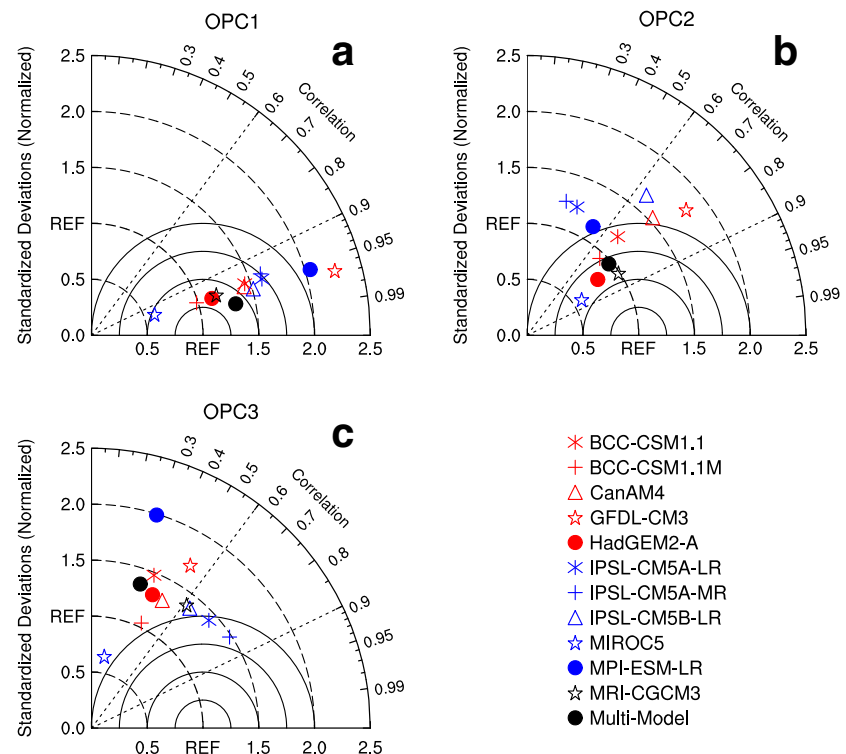

Fig. 5 Taylor diagram for the first three OPCs simulated by 11 CFMIP2 models and the MME, where the reference fields are from GOCCP. The abscissa denotes the pattern standard deviation ratio, and the azimuthal angle indicates the pattern correlation coefficient 
Table 3 Global mean of relative SW/LW cloud radiative forcing (RSCRF/RLCRF) (\%) and original principal component (OPC) (\%)

\begin{tabular}{lrrrrr}
\hline Model & RSCRF & RLCRF & OPC1 & OPC2 & OPC3 \\
\hline BCC-CSM1.1 & -30.4 & 11.2 & 2.9 & -27.4 & 33.4 \\
BCC-CSM1.1M & -28.7 & 10.8 & 1.7 & -20.0 & 19.5 \\
CanAM4 & -25.8 & 9.7 & 5.2 & -28.9 & 18.9 \\
GFDL-CM3 & -26.0 & 10.1 & 0.6 & -29.7 & 34.8 \\
HadGEM2-A & -23.9 & 9.4 & 6.6 & -16.4 & 24.9 \\
IPSL-CM5A-LR & -26.3 & 11.3 & 0.4 & -5.7 & -2.5 \\
IPSL-CM5A-MR & -26.3 & 11.7 & 1.7 & -4.3 & 10.3 \\
IPSL-CM5B-LR & -26.8 & 10.2 & 2.8 & -18.0 & 23.4 \\
MIROC5 & -27.3 & 9.7 & 1.5 & -17.1 & 10.6 \\
MPI-ESM-LR & -25.0 & 9.6 & 1.1 & -10.3 & 47.2 \\
MRI-CGCM3 & -25.1 & 8.9 & -2.0 & -23.6 & 19.4 \\
MME & -25.1 & 9.5 & 3.8 & -18.2 & 31.1 \\
OBS & -24.9 & 9.9 & 9.5 & -25.7 & 3.2 \\
\hline
\end{tabular}

value and standard deviation on SRCs, whose absolute values directly reflect the relative importance of OPCs in determining $\mathrm{RSCRF} / \mathrm{RLCRF}$, the relation between which are given in Eq. (7). All the regression equations ( $F$-test) and PCs (Student $t$ test) pass the significance test at the $99 \%$ confidence level.

\subsubsection{Dependence of RSCRF/RLCRF on CVS modes (SRCs and $R C s)$}

The absolute values of SRCs (Fig. 6a, b) directly reflect the influencing degree of SPCs on RSCRF/RLCRF, and signs of them denote positive or negative dependent relation of RSCRF/RLCRF to SPCs. It is found that the largest relative contribution to RSCRF is from SPC1, then from SPC2, and the least from SPC3 (Fig. 6a), whereas SPC2 contributes the largest to RLCRF, and then SPC3 and SPC1 as shown in observations (Fig. 6b). In most cases, CFMIP2 models simulate the sign-consistent dependence of RSCRF/RLCRF to SPCs, except for that of RLCRF to SPC1, where only half of the models give the right sign. Overall, CFMIP2 models tend to overestimate the relative contributions of SPC1 (10/12 models) and SPC3 (9/12 models) to RSCRF, whereas underestimate that of SPC2 (10/12 models) compared to observations (Fig. 6a). In contrast, CFMIP2 models tend to underestimate the relative contribution of SPC1 (9/12 models) and SPC2 (12/12 models) to RLCRF, whereas overestimate that of SPC3 (12/12 models) compared to observations (Fig. 6b).

RCs (Fig. 6c, d) are completely sign consistent with SRCs, implying coherent dependent relation of RSCRF/RLCRF to them. Considering that Eq. (5) is strictly established if global mean RSCRF/RLCRF and OPCs are substituted, RCs may represent the SW extinction efficiency for RSCRF (i.e. absorbing and scattering ability to SW radiation) or LW emission efficiency for RLCRF corresponding to unit global mean OPC (hereafter unit OPC). RCs may also be interpreted to a large extent as the difference in SW EOD for RSCRF or cloud top height for RLCRF between positive and negative phase clouds in CVS modes (Fig. 1) in unit OPC. According to Eq. (3), unit OPC depends on two factors: One is eigenvectors (i.e. CVS modes in Fig. 1), and the other is global mean vertical profiles of cloud cover (Fig. 7). CVS modes have been discussed in detail in Sects. 3.1 and 3.2, and here, we focus on the mean cloud vertical profiles. Two peaks are observed in GOCCP cloud profile, one of which is located below $3 \mathrm{~km}$, corresponding to abundant optically-thick stratocumulus cloud over the oceans, and the other is around $8 \mathrm{~km}$, mainly contributed by mi-latitude high clouds (Wang et al. 2014b). The most notable difference in global mean cloud vertical profiles is that high clouds are markedly overestimated with the peak at $9-12 \mathrm{~km}$, whereas middle and low clouds are typically underestimated in most CFMIP2 models compared GOCCP (Fig. 7b). This feature may imply compensation between cloud cover and cloud REs in climate models to obtain a better match between simulated and observed TOA radiation balance, that is, models tend to overestimate (underestimate) the REs of low (high) clouds, which may be associated with the overestimation of liquid cloud water contents and possible underestimation of ice cloud water contents in most climate models (Jiang et al. 2012; Wang et al. 2014a). The overestimation of REs in low clouds is also known as the 'too few, too bright' low-cloud problem (Karlsson et al. 2008; Nam et al. 2012).

OPC1 acts to intensify RSCRF corresponding to its unit change as given in observations, indicating in unit OPC1 that the REs of positive phase clouds (mainly low/middle clouds) dominate those of negative phase clouds (high clouds) in THCM. Eight out of 12 models (except two BCC-CSM models, IPSL-CM5B-LR and MIROC5) are found to slightly underestimate the SW REs in unit OPC1, which may be mainly caused by more high clouds (corresponding to negative phase) and fewer low clouds (corresponding to positive phase) in unit OPC1 simulated by these models (Fig. 7b), in view of basically consistent eigenvectors in THCM (Fig. 1a) and the known possible underestimation (overestimation) of REs in high (low) clouds. It is noted that MIROC5 simulated less $\mathrm{mid} /$ high clouds and more low clouds (Fig. 7), resulting in obvious overestimation of SW REs in unit OPC1. OPC2 acts to weaken RSCRF in observations, meaning that REs of negative phase clouds in SACM (Fig. 1b) are predominant over those of positive phase clouds (Fig. 6c). Most models, except two (i.e. BCC CSM1.1 (m) and MRI CGCM3), underestimate the RSCRF contribution by unit OPC2 or even simulate the opposite sign, contributing to damp the weakening of RSCRF as observed. This feature may be qualitatively explained from three aspects. First, biases in most models tend to increase the proportion of high clouds and decrease that in 

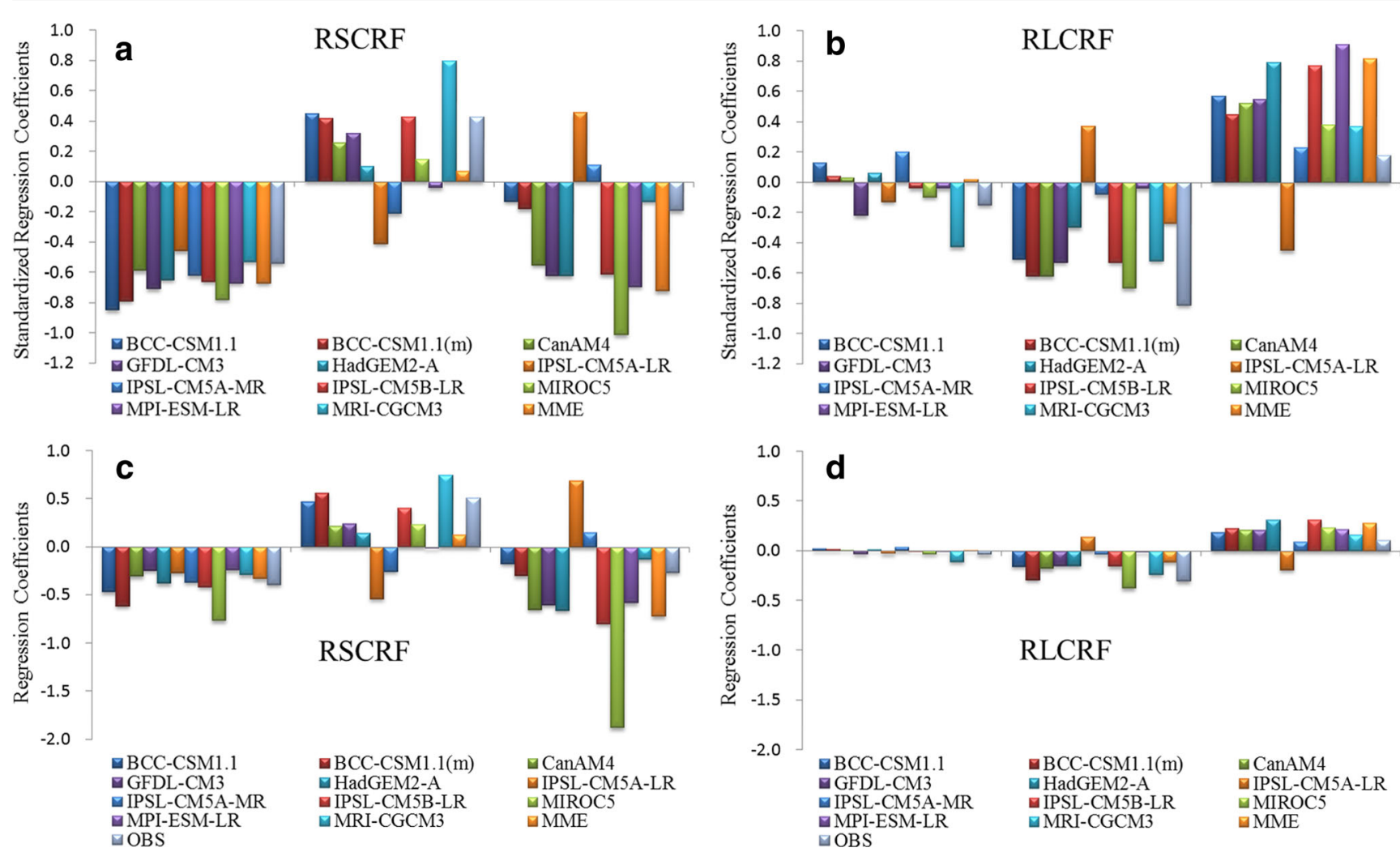

Fig. 6 a, b Standardized and $\mathbf{c}, \mathbf{d}$ ordinary regression coefficients as calculated from the multiple linear regression of RSCRF/RLCRF on the first three PCs

lower levels in negative phase (Fig. 7), which contribute to decrease the REs difference between the two phases in SACM. Second, the fact of underestimation (overestimation) of REs in high (low) clouds further reduces the REs difference. Thirdly, remarkable biases in SACM eigenvectors around 9-12 km may greatly weaken the REs corresponding to negative phase clouds in SACM (acting to reduce RCs) or even produce positive clouds at $9-12 \mathrm{~km}$, producing RCs with the opposite sign in some models (e.g. MPI-ESM-LR and two IPSL-CM5A models). OPC3 acts to intensify RSCRF with its
Fig. 7 Global mean vertical profiles of a cloud cover in CFMIP2 models and GOCCP, and $\mathbf{b}$ cloud cover biases compared to GOCCP in CFMIP2 models (units: \%). Horizontal dashed lines indicate boundaries of ISCCP high, middle and low clouds at 3.36 and $6.72 \mathrm{~km}$, respectively

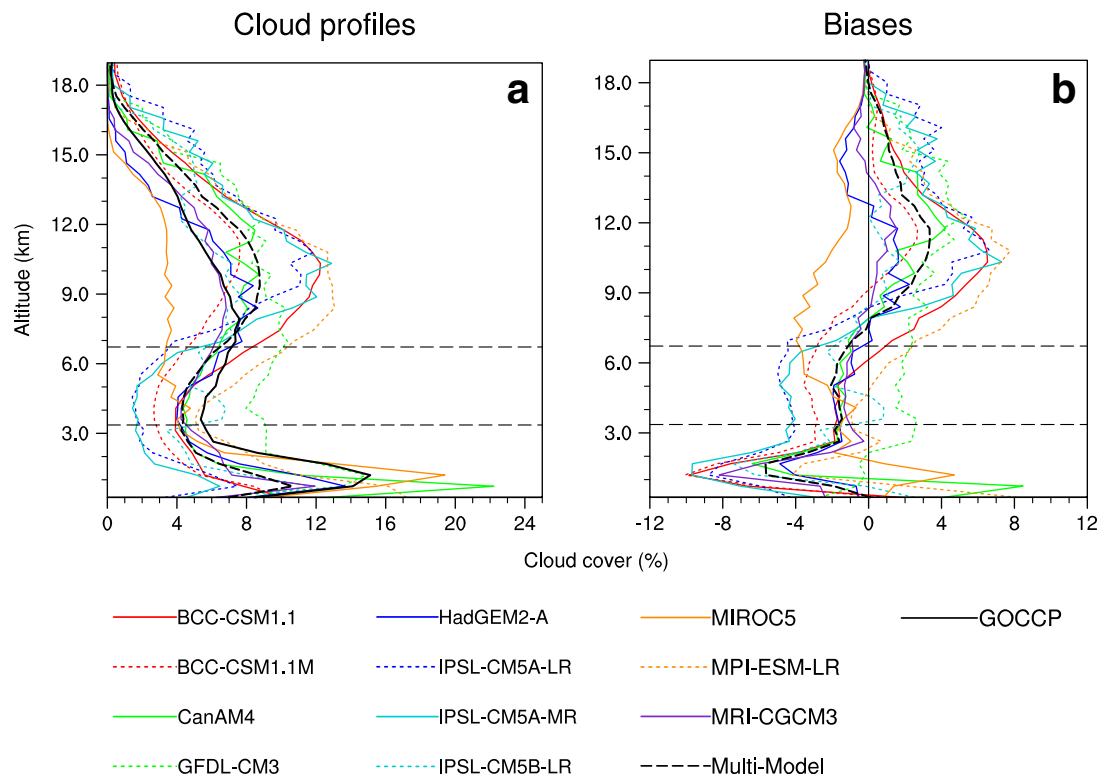


unit change in observations, indicating the domination of REs in positive phase clouds on those in negative phase clouds. The RSCRF corresponding to unit OPC3 is markedly overestimated by seven models (CanAM4, GFDL-CM3, HadGEM2-A, IPSL-CM5B-LR, MIROC5, MPI-ESM-LR and $\mathrm{MME}$ ), which commonly feature stronger positive peak in low/middle cloud levels (Fig. 1c), together with REs overestimation in low clouds, resulting in larger REs in positive phase clouds and then stronger RSCRF in unit OPC3 compared to observations.

The RLCRF from OPCs mainly depends on the difference in cloud top temperature (the lower the temperature, the stronger the RLCRF) as well as the absolute weight of top-level clouds between the two phases in CVS modes (Fig. 1). As a result, OPC3 acts to intensify the RLCRF in observations, opposite to OPC1 and OPC2, although its cloud top height decreases with unit increase in OPC1, due mainly to the larger weight of positive eigenvectors associated with top-level clouds. Overall, CFMIP2 models tend to underestimate or simulate the opposite sign of RLCRF RCs by OPC1 and OPC2 compared to observations, except MRI-CGCM3 for OPC1 and MIROC5 for OPC2, whereas overestimate the relative RLCRF contribution by OPC3 except two IPSL-CM5A models (Fig. 6b). Biases of RLCRF RCs also depend on biases in CVS modes (Fig. 1) as well as those in global mean cloud vertical profiles (Fig. 7). Different from RSCRF, high cloud cover biases in cloud profiles may play dominant roles in determining RLCRF biases compared to low/middle cloud cover biases. Considering these features, above-mentioned RSCRF RCs biases may be mainly resulted from overestimated high clouds especially around 9-12 km (Fig. 7b) as well as the abnormal peaks of eigenvectors at 9$12 \mathrm{~km}$ in SACM and ECCM (Fig. 1b, c).

\subsubsection{Global mean RSCRF/RLCRF biases from CVS modes}

Compared to CERES observations on global mean RSCRF and RLCRF ( -24.9 and 9.9\%), CFMIP2 models tend to overestimate the RSCRF intensity except HadGEM2-A, while one half of the models simulate opposite biases to the other half regarding RLCRF compared to CERES (Table 3). By substituting the global mean of OPCs into the original regression equations, the global mean RSCRF/RLCRF contribution from each OPC is calculated for both models and observations. The signs of global mean RSCRF contributed by OPCs are correctly simulated by $11 / 12$ (except MRICGCM3), 9/12 (except IPSL-CM5A-LR, IPSL-CM5A-MR and MPI-ESM-LR) and 11/12 (except IPSL-CM5A-MR) CFMIP2 models for OPC1, OPC2 and OPC3, respectively. Only 5/12 models capture the correct signs of global mean RLCRF contributions from OPC1, whereas 11/12 (except IPSL-CM5A-LR) and all models simulate the correct signs of those from OPC2 and OPC3, respectively (data not shown).
The global mean biases of RSCRF/RLCRF contributed by OPCs are shown in Fig. 8a b, from which remarkable biases are found for RSCRF (RLCRF) compared to observations, i.e. $-3.7 \%(-0.3 \%)$ for OPC1, $-13.2 \%(7.8 \%)$ for OPC2 and $-0.9 \%(0.4 \%)$ for $\mathrm{OPC} 3$, respectively. RSCRF intensity contributed by OPC3 are markedly overestimated by $11 / 12$ models (except IPSL-CM5A-MR), whereas those from OPC1 and OPC2 are underestimated except one model (MRI-CGCM3) in the case of OPC2 compared to observations (Fig. 8a). RSCRF intensity underestimation from OPC2 may also reflect that cloud radiative forcing biases in downwelling regimes (with biases weakening RSCRF) are much larger than those in upwelling regimes (with biases strengthening RSCRF) (Dolinar et al. 2015), which also applies to the RLCRF biases from OPC2 below. Overall, contribution from OPC3 predominates over contributions from OPC1 and OPC2 in most models. This indicates that ESCM, with the least explained variance, may play an essential role in the overestimation of RSCRF intensity among CFMIP2 models (Table 3).

Although no system RLCRF bias relative to observations is simulated globally among CFMIP2 models (Table 3), biases from three OPCs show remarkable consistency among models (Fig. 8b). That is, RLCRF intensity contributed by OPCs are consistently overestimated (underestimated) in OPC3 (OPC1 and OPC2) by all models compared to observations. It is noted that the RLCRF biases from OPC1 are very small (generally lower than $0.5 \%$ ) although obvious overestimation of high clouds observed in both the tropics and the middle-high latitudes (data not shown). This is due mainly to the opposite roles that high clouds play in RLCRF in the two regions and the cancellation between them. The RLCRF biases from OPC2 and OPC3 are obviously larger than those from OPC1. However, these biases have opposite signs and offset each other to a large extent, resulting in reduced contributions to RLCRF in CFMIP2 models.

\subsubsection{Decomposition of $R S C R F / R L C R F$ biases}

Based on Eq. (7), RSCRF and RLCRF biases from different OPCs are further decomposed into three parts, that is, RC bias term, OPC bias term and their joint effect, which are shown in Fig. $8 \mathrm{c}-\mathrm{h}$. RC bias term denotes the biases from difference in REs corresponding to unit OPC between models and observations, while OPC bias term mainly refers to biases from cloud cover differences between models and observations.

Similar features are found in bias decomposition between RSCRF and RLCRF. Underestimation of RSCRF/RLCRF intensity from OPC1 (Fig. 6c, d) is mainly from OPC biases (Fig. 8e, f), featured by consistent underestimation of global mean OPC1 (Table 3), which mainly come from the overestimated high clouds in the tropics in most of the models (Fig. 4). In contrast, RSCRF biases from RCs and the joint 

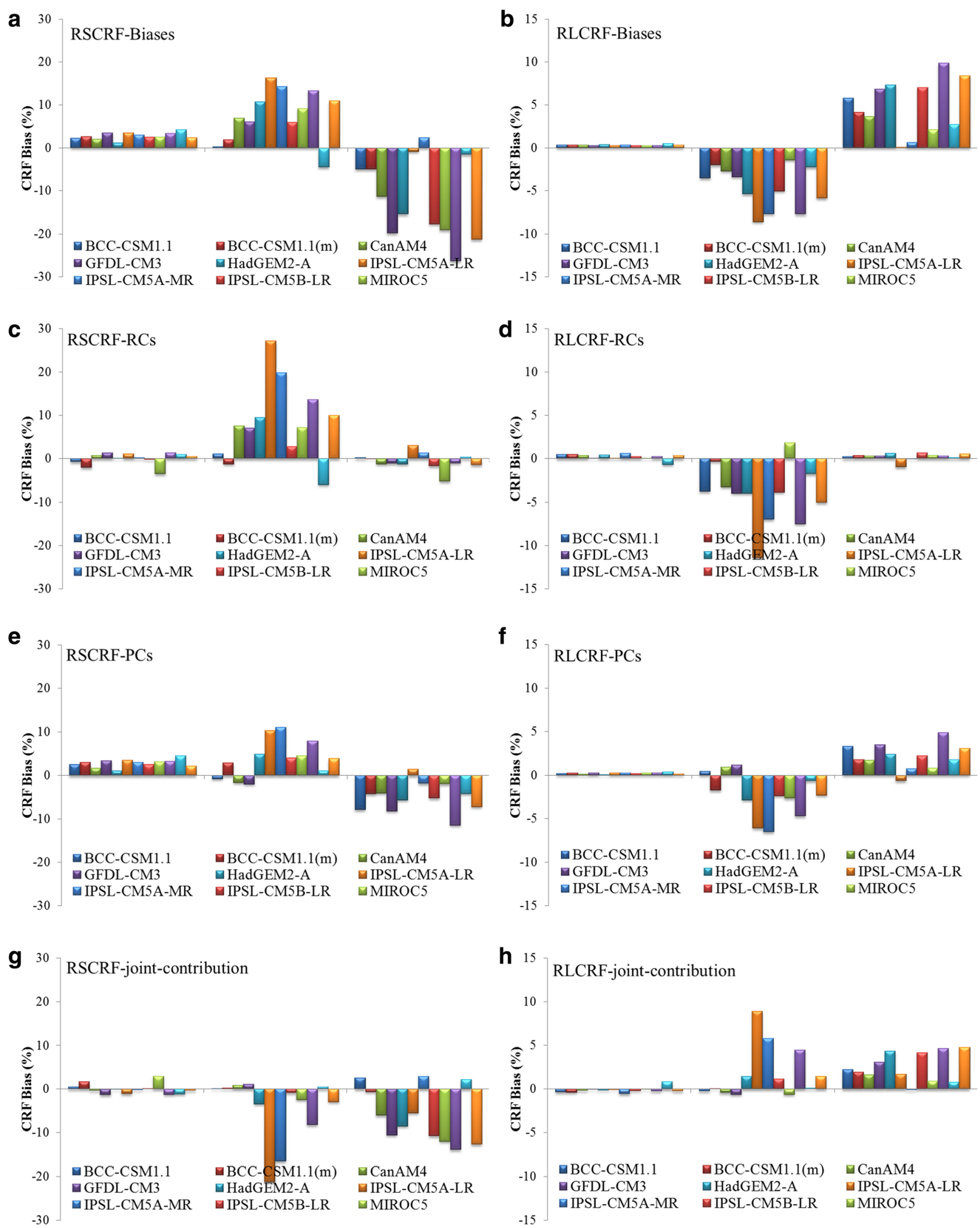

Fig. 8 Global mean a RSCRF and b RLCRF biases compared to observations. $\mathbf{c}, \mathbf{e}, \mathbf{g}$ RSCRF and $\mathbf{d}, \mathbf{f}, \mathbf{h}$ RLCRF biases contributed by regression coefficient biases (upper row), principal component biases (middle row) and both of them (units: \%) 
contribution of RC and OPC cancel each other greatly, due to the opposite sign between global mean OPC1 and OPC1 bias in CFMIP2 models (Table 3). For OPC2, underestimation of RSCRF/RLCRF intensity mainly arises from RC biases (Fig. 8c, d) as well as OPC biases (Fig. 8e, f), corresponding to smaller absolute coefficients (means underestimation of REs by unit OPC2, see Fig. 6c, d) and larger global mean OPC2 in most models (Table 3 and Fig. 4), whereas the joint contribution tends to take the opposite effect (Fig. 8g, h). Overestimation of RSCRF/RLCRF intensity from OPC3 is contributed by overestimated OPC3 (Table 3 and Fig. 4), also added up by the joint contribution from RC and OPC.

\subsection{Discussion}

A question that needs to be addressed here is why the CVS biases and their REs have been produced by CFMIP2 models? The answer may lie on two aspects, cloud/radiation parameterizations and the relevant large-scale environmental fields simulated by those models, between which complex feedback processes exist but cannot be separated from each other in the present study. However, we notice the remarkable improvement in the simulation of CVS modes and their REs in IPSLCM5B-LR (Figs. 1 and 6), wherein the convective boundary layer and cumulus clouds are better represented compared to IPSL-CM5A models (Hourdin et al. 2013).

Data uncertainty is still an inevitable problem in the GOCCP and CERES datasets, which may come from multiple sources, e.g. spatial and temporal sampling, retrieving algorithm and even accuracy of satellite sensors (Stubenrauch et al. 2013; Young et al. 2013). In addition, not all information for certain identified cloud type is constrained in the relevant CVS mode, although they may be physically associated. For example, tropical deep convective clouds are mainly explained by THCM; however, part of information is also included in other two CVS modes. As a final note, the physical explanations on RCs are more qualitative rather than quantitative, which may be not exactly but do contribute to a better understanding of RCs.

\section{Summary}

In this paper, the leading CVS modes simulated by 11 CFMIP2 models and the MME are evaluated using PCA method against the GOCCP data set. The REs of these modes are further accessed in terms of PCR based on CERES radiative fluxes. Main conclusions are listed as follows.

1. The GOCCP data set reveals three leading CVS modes, i.e. tropical high cloud mode (THCM), subtropical anticyclonic cloud mode (SACM) and extratropical cyclonic cloud mode (ECCM). THCM mainly reflect the contrast between tropical high clouds and clouds from PBL to about $10 \mathrm{~km}$ in middle and high latitudes. SACM is closely associated with middle-high clouds in tropical convective cores, few-cloud regimes in subtropical anticyclonic regions and stratocumulus over subtropical eastern oceans. ECCM mainly corresponds to clouds along extratropical cyclonic regions, generally characterized by an asymmetric dipole structure. CFMIP2 models consistently reproduce the THCM and corresponding SPCs quite well, depicting the fundamental latitude-altitude structure of cloud cover. SACM and ECCM are generally poorly simulated mainly in vertical structure relative to their standardized horizontal loadings (i.e. SPCs) compared to GOCCP. In addition, pattern standard deviations of all three OPCs are simulated larger than that in GOCCP by most CFMIP2 models, and OPCs are consistently underestimated (overestimated) for THCM (SACM and ECCM) by CFMIP2 models.

2. Using standardized PCR, the relative importance of OPCs in determining RSCRF/RLCRF (i.e. absolute values of SRCs) is evaluated for CFMIP2 models compared to observations. It is shown that the largest relative contribution to RSCRF is from SPC1, then from SPC2, and the least is from SPC3, whereas SPC2 contributes the largest to RLCRF, and then SPC1 and SPC3, as seen from observations.

3. Ordinary regression coefficients (RCs) denote the SW extinction efficiency for RSCRF (i.e. absorbing and scattering ability to $\mathrm{SW}$ radiation) or LW emission efficiency for RLCRF corresponding to unit global mean OPC. It is difficult to provide exact explanations on RCs but qualitative ones in the present studies, mainly due to their dependence on multiple factors, e.g. global mean cloud vertical profiles (features by underestimation of low/middle clouds and overestimation of high clouds) and CVS modes (featured by remarkable differences in SACM and ECCM).

OPC1 and OPC3 (OPC3) act to intensify RSCRF (RLCRF), whereas OPC2 (OPC1 and OPC2) takes the opposite effect corresponding to its unit change as given in observations. CFMIP2 models tend to overestimate (underestimated or simulate the opposite sign) RSCRF/ RLCRF radiative effects (REs) of ECCM (THCM and SACM) in unit global mean OPC compared to observations. These RE biases may be attributed to two factors, one of which is underestimation (overestimation) of low/ middle clouds (high clouds) (also known as stronger (weaker) REs in unit low/middle (high) clouds) in simulated global mean cloud profiles, the other is eigenvector biases in CVS modes (especially for SACM and ECCM).

4. The global mean RSCRF and RLCRF biases caused by three CVS modes are calculated based on the ordinary PCR equations and global mean OPCs. The majority of 
CFMIP2 models tend to underestimate global mean RSCRF/RLCRF intensity from OPC1 and OPC2, whereas to overestimate them by $\mathrm{OPC} 3$ as compared to observations. Further examination shows that RSCRF/RLCRF biases from OPC1 mainly caused by OPC biases, that is, consistent underestimation of OPC1 by CFMIP2 models. $\mathrm{RC}$ biases as well as OPC overestimation jointly contribute to global mean RSCRF/RLCRF biases contributed by OPC2. In addition, RSCRF/RLCRF biases from OPC3 are mainly contributed by $\mathrm{OPC} 3$ overestimation as well as the joint contribution from $\mathrm{RC}$ and $\mathrm{OPC}$.

Our results have shown that the THCM and its REs has been better reproduced in most CFMIP2 models compared to SACM and ECCM. Although the SACM and ECCM are poorly simulated in most models, their standardized horizontal loadings are overall reasonably captured (Fig. 2), indicating that the improvement on CVS, especially cloud parameterization associated with particular physical processes (e.g. downwelling regimes with the Hadley circulation, extratropical storm tracks and others), may be crucial to reduce the CRF biases simulated by climate models.

Acknowledgements This work was supported by the National Natural Science Foundation of China (grants 41275077 and 41475069). We are grateful to the World Climate Research Programme's Working Group on Coupled Modelling, which is responsible for the CMIP. We thank the Climate Modelling Groups (listed in Table of this paper) for producing their model output and making it available.

Open Access This article is distributed under the terms of the Creative Commons Attribution 4.0 International License (http:// creativecommons.org/licenses/by/4.0/), which permits unrestricted use, distribution, and reproduction in any medium, provided you give appropriate credit to the original author(s) and the source, provide a link to the Creative Commons license, and indicate if changes were made.

\section{References}

Ackerman TP, Stokes GM (2003) The atmospheric radiation measurement program. Phys Today 56:38-44

Bodas-Salcedo A, Webb MJ, Bony S, Chepfer H, Dufresne J-L, Klein SA, Zhang Y, Marchand R, Haynes JM, Pincus R (2011) COSP: satellite simulation software for model assessment. Bull Am Meteorol Soc 92:1023-1043

Cesana G, Chepfer H (2012) How well do climate models simulate cloud vertical structure? A comparison between CALIPSO? GOCCP satellite observations and CMIP5 models. Geophys Res Lett 39: L20803

Cesana G, Kay JE, Chepfer H, English JM, de Boer G (2012) Ubiquitous low-level liquid-containing Arctic clouds: new observations and climate model constraints from CALIPSO-GOCCP. Geophys Res Lett 39:L20804

Chepfer H, Bony S, Winker D, Chiriaco M, Dufresne J-L, Sèze G (2008) Use of CALIPSO lidar observations to evaluate the cloudiness simulated by a climate model. Geophys Res Lett 35:L15704
Chepfer H, Bony S, Winker D, Cesana G, Dufresne J, Minnis P, Stubenrauch C, Zeng S (2010) The GCM-oriented CALIPSO cloud product (CALIPSO-GOCCP). J Geophys Res 115:D00H16

Dessler A, Palm S, Spinhirne J (2006) Tropical cloud-top height distributions revealed by the ice, cloud, and land elevation satellite (ICESat)/geoscience laser altimeter system (GLAS). Journal of Geophysical Research: Atmospheres (1984-2012) 111:D12215

Dolinar E, Dong X, Xi B, Jiang J, Su H (2015) Evaluation of CMIP5 simulated clouds and TOA radiation budgets using NASA satellite observations. Clim Dyn 44:2229-2247

Donner LJ, Wyman BL, Hemler RS, Horowitz LW, Ming Y, Zhao M, Golaz J-C, Ginoux P, Lin SJ, Schwarzkopf MD, Austin J, Alaka G, Cooke WF, Delworth TL, Freidenreich SM, Gordon CT, Griffies SM, Held IM, Hurlin WJ, Klein SA, Knutson TR, Langenhorst AR, Lee H-C, Lin Y, Magi BI, Malyshev SL, Milly PCD, Naik V, Nath MJ, Pincus R, Ploshay JJ, Ramaswamy V, Seman CJ, Shevliakova E, Sirutis JJ, Stern WF, Stouffer RJ, Wilson RJ, Winton M, Wittenberg AT, Zeng F (2011) The dynamical Core, physical parameterizations, and basic simulation characteristics of the atmospheric component AM3 of the GFDL global coupled model CM3. J Clim 24:3484-3519

Dufresne JL, Foujols MA, Denvil S, Caubel A, Marti O, Aumont O, Balkanski Y, Bekki S, Bellenger H, Benshila R, Bony S, Bopp L, Braconnot P, Brockmann P, Cadule P, Cheruy F, Codron F, Cozic A, Cugnet D, de Noblet N, Duvel JP, Ethé C, Fairhead L, Fichefet T, Flavoni S, Friedlingstein P, Grandpeix JY, Guez L, Guilyardi E, Hauglustaine D, Hourdin F, Idelkadi A, Ghattas J, Joussaume S, Kageyama M, Krinner G, Labetoulle S, Lahellec A, Lefebvre MP, Lefevre F, Levy C, Li ZX, Lloyd J, Lott F, Madec G, Mancip M, Marchand M, Masson S, Meurdesoif Y, Mignot J, Musat I, Parouty S, Polcher J, Rio C, Schulz M, Swingedouw D, Szopa S, Talandier C, Terray P, Viovy N, Vuichard N (2013) Climate change projections using the IPSL-CM5 earth system model: from CMIP3 to CMIP5. Clim Dyn 40:2123-2165

Golaz J-C, Horowitz LW, Levy H II (2013) Cloud tuning in a coupled climate model: impact on twentieth century warming. Geophys Res Lett 40:2246-2251

Hahn CJ, Rossow WB, Warren SG (2001) ISCCP cloud properties associated with standard cloud types identified in individual surface observations. J Clim 14:11-28

Hourdin F, Grandpeix J-Y, Rio C, Bony S, Jam A, Cheruy F, Rochetin N, Fairhead L, Idelkadi A, Musat I, Dufresne J-L, Lahellec A, Lefebvre M-P, Roehrig R (2013) LMDZ5B: the atmospheric component of the IPSL climate model with revisited parameterizations for clouds and convection. Clim Dyn 40:2193-2222

Huang Y, Protat A, Siems ST, Manton MJ (2014) A-train observations of maritime midlatitude storm-track cloud systems: comparing the Southern Ocean against the North Atlantic. J Clim 28:1920-1939

Jiang JH, Su H, Zhai C, Perun VS, Del Genio A, Nazarenko LS, Donner LJ, Horowitz L, Seman C, Cole J (2012) Evaluation of cloud and water vapor simulations in CMIP5 climate models using NASA "Atrain" satellite observations. J Geophys Res 117:D14105

Karlsson J, Svensson G, Rodhe H (2008) Cloud radiative forcing of subtropical low level clouds in global models. Clim Dyn 30:779-788

Kato S, Loeb NG, Rose FG, Doelling DR, Rutan DA, Caldwell TE, Yu L, Weller RA (2013) Surface irradiances consistent with CERESderived top-of-atmosphere shortwave and longwave irradiances. J Clim 26:2719-2740

Kay JE, Hillman BR, Klein SA, Zhang Y, Medeiros B, Pincus R, Gettelman A, Eaton B, Boyle J, Marchand R (2012) Exposing global cloud biases in the community atmosphere model (CAM) using satellite observations and their corresponding instrument simulators. J Clim 25:5190-5207

Martin GM, Ringer MA, Pope VD, Jones A, Dearden C, Hinton TJ (2006) The physical properties of the atmosphere in the new 
Hadley Centre global environmental model (HadGEM1). Part I: Model Description and Global Climatology J Clim 19:1274-1301

Mauritsen T, Stevens B, Roeckner E, Crueger T, Esch M, Giorgetta M, Haak H, Jungclaus J, Klocke D, Matei D (2012) Tuning the climate of a global model. J Adv Model Earth Syst 4:M00A01

Nam C, Bony S, Dufresne JL, Chepfer H (2012) The 'too few, too bright' tropical low-cloud problem in CMIP5 models. Geophys Res Lett 39: L21801

North GR, Bell TL, Cahalan RF, Moeng FJ (1982) Sampling errors in the estimation of empirical orthogonal functions. Mon. Wea. Rev. 110: 699-706

Qian Y, Long CN, Wang H, Comstock JM, McFarlane SA, Xie S (2012) Evaluation of cloud fraction and its radiative effect simulated by IPCC AR4 global models against ARM surface observations. Atmos Chem Phys 12:1785-1810

Rossow WB, Schiffer RA (1999) Advances in understanding clouds from ISCCP. Bull Am Meteorol Soc 80:2261-2287

Rossow WB, Zhang Y (2010) Evaluation of a statistical model of cloud vertical structure using combined CloudSat and CALIPSO cloud layer profiles. J Clim 23:6641-6653

Rossow WB, Zhang Y, Wang J (2005) A statistical model of cloud vertical structure based on reconciling cloud layer amounts inferred from satellites and radiosonde humidity profiles. J Clim 18:35873605

Stephens GL (2005) Cloud feedbacks in the climate system: a critical review. J Clim 18:237-273

Stephens GL, Vane DG, Boain RJ, Mace GG, Sassen K, Wang Z, Illingworth AJ, O'Connor EJ, Rossow WB, Durden SL (2002) The CloudSat mission and the A-train. Bull Am Meteorol Soc 83: $1771-1790$

Stevens B, Giorgetta M, Esch M, Mauritsen T, Crueger T, Rast S, Salzmann M, Schmidt H, Bader J, Block K, Brokopf R, Fast I, Kinne S, Kornblueh L, Lohmann U, Pincus R, Reichler T, Roeckner E (2013) Atmospheric component of the MPI-M earth system model: ECHAM6. J Adv Model Earth Syst 5:1-27

Stubenrauch C, Rossow W, Kinne S, Ackerman S, Cesana G, Chepfer H, Di Girolamo L, Getzewich B, Guignard A, Heidinger A (2013) Assessment of global cloud datasets from satellites: project and database initiated by the GEWEX radiation panel. Bull Am Meteorol Soc 94:1031-1049

Taylor KE (2001) Summarizing multiple aspects of model performance in a single diagram. J Geophys Res 106:7183-7192
Taylor KE, Stouffer RJ, Meehl GA (2012) An overview of CMIP5 and the experiment design. Bull Am Meteorol Soc 93:485-498

von Salzen K, Scinocca JF, McFarlane NA, Li J, Cole JNS, Plummer D, Verseghy D, Reader MC, Ma X, Lazare M, Solheim L (2013) The Canadian fourth generation atmospheric global climate model (CanAM4). Part I: Representation of Physical Processes Atmosphere-Ocean 51:104-125

Wang J, Rossow WB, Zhang Y (2000) Cloud vertical structure and its variations from a 20-yr global rawinsonde dataset. J Clim 13:30413056

Wang F, Yang S, Wu T (2014a) Radiation budget biases in AMIP5 models over the east Asian monsoon region. Journal of Geophysical Research: Atmospheres 119:13400-13426

Wang F, Xin X, Wang Z, Cheng Y, Zhang J, Yang S (2014b) Evaluation of cloud vertical structure simulated by recent BCC_AGCM versions through comparison with CALIPSO-GOCCP data. Adv Atmos Sci 31:721-733

Warren SG, Hahn CJ, London J, Chervin RM, Jenne RL, 1988: Global distribution of total cloud cover and cloud type amounts over the ocean. NCAR Tech. Note NCAR/TN-31 7 + STR, 212 pp

Watanabe M, Emori S, Satoh M, Miura H (2009) A PDF-based hybrid prognostic cloud scheme for general circulation models. Clim Dyn 33:795-816

Winker DM, Vaughan MA, Omar A, Hu Y, Powell KA, Liu Z, Hunt WH, Young SA (2009) Overview of the CALIPSO mission and CALIOP data processing algorithms. J Atmos Ocean Technol 26:2310-2323

Wood R (2012) Stratocumulus Clouds. Mon Wea Rev 140:2373-2423

Young SA, Vaughan MA, Kuehn RE, Winker DM (2013) The retrieval of profiles of particulate extinction from cloud-aerosol Lidar and infrared pathfinder satellite observations (CALIPSO) data: uncertainty and error sensitivity analyses. J Atmos Ocean Technol 30:395-428

Yukimoto S, Yoshimura H, Hosaka M, Sakami T, Tsujino H, Hirabara M, Tanaka TY, Deushi M, Obata A, Nakano H, Adachi Y, Shindo E, Yabu S, Ose T, Kitoh A (2011) Meteorological Research InstituteEarth System Model Version 1 (MRI-ESM1): Model Description. Technical Reports of the Meteorological Research Institute No.64: $83 \mathrm{pp}$

Zhang MH, Lin WY, Klein SA, Bacmeister JT, Bony S, Cederwall RT, Del Genio AD, Hack JJ, Loeb NG, Lohmann U, Minnis P, Musat I, Pincus R, Stier P, Suarez MJ, Webb MJ, Wu JB, Xie SC, Yao MS, Zhang JH (2005) Comparing clouds and their seasonal variations in 10 atmospheric general circulation models with satellite measurements. Journal of Geophysical Research: Atmospheres 110:D15S02 